\title{
Characterization of a New Anastomosis Group (AG-W) of Binucleate Rhizoctonia, Causal Agent for Potato Stem Canker
}

\author{
Y. G. Yang, C. Zhao, Z. J. Guo, and X. H. Wu, Department of Plant Pathology, China Agricultural University, Beijing 100193, China
}

\begin{abstract}
Yang, Y. G., Zhao, C., Guo, Z. J., and Wu, X. H. 2015. Characterization of a new anastomosis group (AG-W) of binucleate Rhizoctonia, causal agent for potato stem canker. Plant Dis. 99:1757-1763.

Two binucleate Rhizoctonia (BNR) isolates were recovered from potato cankered stems in Heilongjiang Province, northeastern China. Their cultural appearance on potato dextrose agar remained whitish as the cultures aged. White monilioid cells formed in the fluffy aerial hyphae, whereas no sclerotia appeared during the incubation. The two isolates could anastomose with each other, but they failed to anastomose with reference strains of BNR from AG-A to AG-Q, and AG-U. Analyses of restriction fragment length polymorphism (RFLP) of internal transcribed spacer of ribosomal DNA (rDNA-ITS) regions confirmed that these two isolates

differed from the reference strains. The phylogenetic tree based on the sequences of rDNA-ITS regions showed that they were located in a distinct clade from other BNR AGs. These collective results suggested that the isolates recovered from potato in this study belonged to a new BNR AG designated as AG-W. Pathogenicity tests under glasshouse conditions revealed that both isolates were able to cause brown, dry, and slightly sunken lesions on potato subterranean stems. To our knowledge, this is the first report of the AG-W causing potato disease in China as well as worldwide.
\end{abstract}

Binucleate Rhizoctonia (BNR; teleomorphs: Ceratobasidium spp.) are distributed worldwide in both agricultural and forest soils (González et al. 2006). On the basis of hyphal fusion, 22 anastomosis groups (AGs) have been described. Ogoshi et al. classified BNR isolates from Japan into 17 anastomosis groups (from AG-A to AG-Q) (Ogoshi 1985; Ogoshi et al. 1979). In North America, Burpee et al. (1980) assigned BNR isolates to seven Ceratobasidium anastomosis groups (from CAG-1 to CAG-7). Ogoshi et al. (1983) pointed out that CAG-1 isolates were able to anastomose with members of AG-D, while CAG-2 corresponded to AG-A, CAG-4 corresponded to AG-F, and CAG-3 and CAG-6 corresponded to AG-E. Sneh et al. (1991) designated CAG-5 and CAG-7 as new AGs of AG-R and AG-S, respectively. In 2005, Hyakumachi et al. reported two new binucleate anastomosis groups (AG-T and AG-U) isolated from cut-flower roses. Recently, BNR isolates collected from taro and ginger in Yunnan Province of China were assigned to a new anastomosis group, AG-V (Dong et al. 2013). Since AG-J and AG-N isolates have been excluded from Rhizoctonia spp. (Cubeta et al. 1991; Sharon et al. 2008), representative isolates of AG-M were lost (Sneh et al. 1991), and AG-T isolates were confirmed to belong to AG-A (Sharon et al. 2008); only 18 BNR AGs are currently known.

Based on other characteristics such as frequency of anastomosis, cultural morphology, pathogenicity, and sequence analysis of the internal transcribed spacer (ITS) region of ribosomal DNA genes (rDNA), AG-B has been further divided in to AG-Ba, AG-Bb, and AG-B(o) (Sneh et al. 1991), while AG-D was subdivided in to AG-D I, AG-D II, and AG-D III (Hayakawa et al. 2006; Toda et al. 1999). It was suggested that subgroups might also exist in AG-F (Sharon et al. 2007) and AG-P (Sharon et al. 2008).

Although the classical hyphal fusion method is valid for the identification of Rhizoctonia spp. into anastomosis groups, it is insufficient because some isolates of certain AGs failed to anastomose with certain isolates of the same AG. For example, several isolates within AG-P had low fusion frequency (Sharon et al. 2008). On the other hand, some isolates belonging to different AGs were able

Corresponding author: X. H.Wu, E-mail: wuxuehong@cau.edu.cn

Accepted for publication 30 May 2015.

http://dx.doi.org/10.1094/PDIS-01-15-0036-RE

(C) 2015 The American Phytopathological Society to anastomose with each other as Ogoshi reported that AG-I isolates could anastomose with some isolates of AG-C (Sneh et al. 1991). Compared with the conventional hyphal fusion method, restriction fragment length polymorphism (RFLP) analysis of the rDNA-ITS regions can provide quick and reliable results (Liu and Sinclair 1993), which has been used to differentiate subgroups within BNR AG-D (Toda et al. 1999) and $R$. solani AG-1 (Priyatmojo et al. 2001). Currently, DNA sequence analysis of rDNA-ITS region has been recognized as the most appropriate method for classification of Rhizoctonia spp. (Gonzalez et al. 2001; Sharon et al. 2006).

Many BNR isolates have been reported as economically important plant pathogens causing various diseases on a wide range of agricultural crops (Carling et al. 1999; González et al. 2006; Sneh et al. 1991; Wang and Wu 2012). On potato (Solanum tuberosum L.), BNR isolates of AG-A, AG-F, AG-K, and AG-U were reported to cause moderate stem canker symptoms (Miles et al. 2013; Yang and Wu 2013; Yang et al. 2014). In 2014, two binucleate-like Rhizoctonia isolates were recovered from cankered subterraneous potato stems that were collected from two separate fields in Kedong county, the traditional potato growing region in Heilongjiang Province of China. These two isolates failed to anastomose with BNR tester strains representing AG-A to AG-Q and AG-U. The objective of this study was to characterize the two isolates by describing their (i) nuclear conditions; (ii) anastomosis reactions among reference strains of known BNR AGs; (iii) morphological characteristics including hyphal diameter, radial growth rate of colonies, and cultural appearance on potato dextrose agar (PDA); (iv) RFLP pattern and sequence data of the rDNA-ITS regions; and (v) virulence on potato plants.

\section{Materials and Methods}

Sample collection and fungal isolation. In 2014, subterraneous potato (cv. Kexin 13) stems with brown and sunken lesions were collected from commercial fields in Kedong county (latitude $48^{\circ} 09^{\prime} \mathrm{N}$; longitude $126^{\circ} 12^{\prime}$ E) of Heilongjiang Province, northeastern China. Samples were gently washed under running tap water to remove adhering soil and debris, and then were cut into pieces (about $5 \times 5 \mathrm{~mm}$ ) from the margins of the healthy and diseased tissues. Surface disinfestation was performed with $70 \%$ ethanol for $30 \mathrm{~s}$, followed by soaking in $0.5 \%$ sodium hypochlorite for $3 \mathrm{~min}$ and rinsed three times with sterile distilled water. After drying on sterilized filter paper, the fragments were placed on $2 \%$ water agar (WA) containing $50 \mu \mathrm{g} / \mathrm{ml}$ streptomycin sulfate and incubated at $25^{\circ} \mathrm{C}$ for 24 to $72 \mathrm{~h}$. Two fungal isolates with characteristic right angle branches, a septum near the 
branch, and a slight constriction at the branch base were preliminarily identified as Rhizoctonia spp. and were designated as HL-CZ and HLZA. The hyphal tips were transferred onto PDA plates for purification. Following sufficient growth, culture plates were kept at $4{ }^{\circ} \mathrm{C}$ for shortterm storage. For long-term preservation, these isolates were colonized on sterile barley grains and maintained at $4^{\circ} \mathrm{C}$.

Nuclear condition. Isolates HL-CZ and HL-ZA were characterized as either binucleate or multinucleate by the method of Ahvenniemi et al. (2009). A 7-mm-diameter disk of PDA removed from the margin of an actively growing colony was placed on sterilized microscope slides overlaying $2 \%$ WA plate in 9-cm-diameter petri dishes and incubated at $20^{\circ} \mathrm{C}$ in the dark for 24 to $48 \mathrm{~h}$. Developed mycelia were stained with $1 \mu \mathrm{g} / \mathrm{ml} \mathrm{4}$-6-diamidino-2-phenylindole (DAPI) for $10 \mathrm{~min}$ in the dark and the slides subsequently rinsed with sterile distilled water. Nuclei of at least 20 cells of more than one hypha were counted under a fluorescence microscope at $400 \times$ magnification in order to determine the nuclear status of each isolate. Simultaneously, diameters of mature hyphae were measured.

AG determination. The clean-slide method (Kronland and Stanghellini 1988) was used to determine AG identities of the isolates HL-CZ and HL-ZA by observing hyphal anastomosis. Reference strains FuK-600 (AG-A), C484 (AG-Ba), C-350 (AG-Bb), Ao-1-2 (AG-C), Ayu-WP-1 (AG-DI), TAK-14KT (AG-DII), KOU04-12FW (AG-DIII), RH-155 (AG-E), AH-6 (AG-Fb), AH-9 (AG-G), STC-11 (AG-H), AV-2 (AG-I), 55D45 (AG-K), FKO-216 (AG-L), FKO-6-2 (AG-O), C-578 (AG-P), C-620 (AG-Q), and MWR-20 (AG-U) were kindly offered by N. Kondo (Graduate School of Agriculture, Hokkaido University, Sapporo, Japan). Seven millimeter diameter disks of each tested isolate were placed on microscope slides with reference strains separated by 2 to $3 \mathrm{~cm}$. When the hyphae from two sides overlapped, the fungal disks were gently removed from the slide and then the overlapping hyphae were stained with safranin O (Sigma) and 3\% $\mathrm{KOH}$ according to the method reported by Bandoni (1979). The stained area was observed under bright-field optics at $40 \times$ magnification to search for potential fusion events, which were confirmed at higher magnification $(100 \times$ and $400 \times)$. Anastomosis reactions were classified according to Carling (1996) as C0, no interaction; C1, hyphal contact without fusion; $\mathrm{C} 2$, cell wall fused while anastomosing and adjacent cells die; C3, fusion of cell wall and membrane, with no cell death.

Morphological characterization. The morphological characteristics (color, size, and shape of sclerotia and colony pigmentation) of the two isolates growing on PDA at $25^{\circ} \mathrm{C}$ in the dark were continuously examined and recorded every 3 days for at least 3 weeks. Three plates of each isolate were randomly arranged in an incubator. The experiment was repeated to ensure the reproducibility of results.

Radial growth rates. Growth rates of the two isolates were determined at $0,5,10,15,20,25,30,35$, and $40^{\circ} \mathrm{C}$ on PDA. Fungal disks (7 $\mathrm{mm}$ in diameter) from the margin of an actively growing colony were transferred to PDA in a 9-cm-diameter petri dish. Colony radius was measured at 24-h intervals until the colony reached the edge of the petri dish. Each treatment was replicated three times, and the experiment was repeated once.

Induction of teleomorphs. Attempts were made to induce perfect stage of the two isolates on $2 \% \mathrm{WA}, 2 \% \mathrm{~V} 8$ juice agar (18 g of agar plus $20 \mathrm{ml}$ of V8 juice per liter), and with the soil overlay technique (Ogoshi 1976). For each isolate, 10 petri dishes were prepared and incubated at 20 to $23^{\circ} \mathrm{C}$ for 3 weeks. Cultures were examined every second or third day for the presence of hymenia and basidiospores under the microscope.

DNA extraction. Isolates $\mathrm{HL}-\mathrm{CZ}$ and $\mathrm{HL}-\mathrm{ZA}$ and reference strains mentioned above were grown on a cellophane disc placed on PDA media. After 3 to 5 days, mycelia were collected, freezedried, and ground to fine powder in liquid nitrogen. The mycelial powder was suspended with $700 \mu \mathrm{CTAB}$ extraction buffer (100 mM TrisHCl pH 8.0, 20 mM EDTA pH 8.0, 1.4 M NaCl, $20 \mathrm{mM} \beta$-mercaptoethanol, and $2 \% \mathrm{w} / \mathrm{v}$ cetyltrimethylammonium bromide) in 2-ml microcentrifuge tubes and incubated at $65^{\circ} \mathrm{C}$ for 30 min (with intermittent mixing of tube contents). The solution was extracted with an equal volume of chloroform-isoamyl alcohol
$(24: 1, \mathrm{v} / \mathrm{v})$ and centrifuged at $12,000 \mathrm{rpm}$ for $10 \mathrm{~min}$ at room temperature. The resulting supernatant was incubated with $40 \mu \mathrm{g} / \mathrm{ml}$ of $\mathrm{RNase} \mathrm{A}$ at $37^{\circ} \mathrm{C}$ for $30 \mathrm{~min}$. The solution was re-extracted with an equal volume of chloroform-isoamyl alcohol $(24: 1, \mathrm{v} / \mathrm{v})$ and centrifuged at $12,000 \mathrm{rpm}$ for $10 \mathrm{~min}$. The supernatant was mixed with an equal volume of isopropanol and 1/10 volume of $3 \mathrm{M}$ sodium acetate $(\mathrm{pH} 4.8)$ to precipitate genomic DNA. After being centrifuged at $12,000 \mathrm{rpm}$ for $10 \mathrm{~min}$ at room temperature, the resulting pellet was washed twice with $70 \%$ ethanol. Then the pellet was dried under vacuum and dissolved in $50 \mu \mathrm{ldd} \mathrm{H}_{2} \mathrm{O}$. To ensure that each DNA sample was of adequate quality for PCR, UV spectrophotometry (Nanodrop 2000, Thermo, Wilmington, DE) was used to determine the concentration and purity of DNA.

PCR amplification and product purification. The rDNA-ITS regions were amplified from genomic DNA with universal primers ITS1 and ITS4 (White et al. 1990). A total volume of $50 \mu 1$ reaction mixture contained $22 \mu \mathrm{lddH_{2 }}$ O, $25 \mu$ l Premix Ex Taq (Version 2.0, TaKaRa, containing $0.625 \mathrm{U}$ DNA polymerase, $200 \mu \mathrm{M}$ dNTP, and $\left.1.5 \mathrm{mM} \mathrm{Mg}{ }^{2+}\right), 1 \mu \mathrm{l}$ each of primer $(10 \mu \mathrm{M})$, and $1 \mu \mathrm{l}$ DNA $(100 \mu \mathrm{g} / \mathrm{ml})$. Samples containing the same reagents but without DNA were used as negative controls. Amplification was performed in an Eppendorf Mastercycler gradient thermal cycler (Eppendorf, Hamburg, Germany) with the following program: initial denaturation at $94^{\circ} \mathrm{C}$ for $3 \mathrm{~min}$; followed by 30 cycles of denaturing at $94^{\circ} \mathrm{C}$ for $40 \mathrm{~s}$, annealing at $56^{\circ} \mathrm{C}$ for $40 \mathrm{~s}$, and extension at $72^{\circ} \mathrm{C}$ for $1 \mathrm{~min}$; one cycle of extension at $72^{\circ} \mathrm{C}$ for $10 \mathrm{~min}$ and final incubation at $4^{\circ} \mathrm{C}$. After being examined on a $1 \%$ agarose gel, PCR products were washed with $50 \mu \mathrm{l}$ of chloroform, precipitated with $5 \mu \mathrm{l}$ of $3 \mathrm{M}$ sodium acetate and $125 \mu \mathrm{l}$ of $99.5 \%$ ethanol at $-80^{\circ} \mathrm{C}$ for $30 \mathrm{~min}$, and centrifuged. Pellets were washed in $70 \%$ ethanol, dried under vacuum, resuspended in $50 \mu \mathrm{l}$ of Tris-EDTA $(10 \mathrm{mM}$ Tris- $\mathrm{HCl}, \mathrm{pH} 7.5 ; 1 \mathrm{mM}$ EDTA, $\mathrm{pH}$ 8.0) buffer, and stored at $4^{\circ} \mathrm{C}$ until use.

RFLP of rDNA-ITS. The purified PCR product of each isolate was digested separately with restriction enzymes EcoRI, HaeIII, HapII, HhaI, HinfI, and $M b o I$ in accordance with the manufacturer's recommendations (TaKaRa Bio Inc., Dalian, China). The restriction fragments were separated by electrophoresis on $2 \%$ agarose gel and visualized under UV light after staining with ethidium bromide. A molecular marker (20- and 100-bp DNA ladder; TaKaRa) was used as a reference in each gel.

Sequencing and phylogenic analysis of rDNA-ITS region. Purified PCR products from the isolates HL-CZ and HL-ZA were cloned into the vector pMD19-T (TaKaRa) according to the manufacturer's instructions. The cloning reaction mixture was transformed into competent cells of Escherichia coli MC1022 by heat shock at $42^{\circ} \mathrm{C}$ for $90 \mathrm{~s}$, which were then cultured on Luria-Bertani broth media containing $50 \mu \mathrm{g} / \mathrm{ml}$ ampicillin. Colonies verified by PCR were sent to Beijing Sunbiotech Co., Ltd (Beijing, China) for sequencing. The resulting sequences of HL-ZA and HL-CZ were deposited in GenBank as accession numbers KP281807 and KP281808, respectively.

Phylogenetic analysis was performed on the basis of rDNA-ITS sequences of the two BNR isolates from this study and representative strains of known BNR AGs (Table 1) retrieved from GenBank (Copes et al. 2011; Gonzalez et al. 2001; Sharon et al. 2008). Athelia rolfsii isolate FSR-052 (GenBank Accession No. AY684917) was used as the outgroup (Fang et al. 2013; Sharon et al. 2007, 2008). All sequences were aligned using the Clustal W algorithm (Thompson et al. 1994) and obvious errors were adjusted manually. A phylogenetic tree was constructed using MEGA5 software (Tamura et al. 2011) with maximum likelihood (ML) method. Bootstrap support was estimated based on 1,000 pseudoreplicates and only bootstrap values $\geq 70 \%$ are shown in the phylogenetic tree. The percent sequence identity of the rDNA-ITS region was calculated by direct pairwise comparisons within BioEdit software (Hall 2011).

Pathogenicity tests. The pathogenicity of the two isolates was tested using a method modified from Lehtonen et al. (2008). Wheat seeds were moistened with sterile distilled water $(60 \% \mathrm{v} / \mathrm{w})$ in 250 $\mathrm{ml}$ flasks and sterilized by autoclaving twice at $121^{\circ} \mathrm{C}$ for $1 \mathrm{~h}$, with a $24 \mathrm{~h}$ interval. The seeds were cooled at room temperature and spread on the 4-day-old actively growing mycelium of BNR isolates on PDA. The fungus was allowed to colonize the seeds for 3 days at room temperature in the dark. 
Visually asymptomatic potato seed tubers (cv. Favorita) sprouted at room temperature in the dark until the sprouts were about $3 \mathrm{~mm}$ long. One sprouted tuber was placed in a sterile plastic pot (1 liter) filled to $3 \mathrm{~cm}$ depth of sand and sawdust mixture $(1: 2 \mathrm{v} / \mathrm{v}$, dry heat sterilization at $161^{\circ} \mathrm{C}$ for $4 \mathrm{~h}$ before use). The amount of inoculum was standardized as one wheat seed for each plant. The wheat seed was placed $10 \mathrm{~mm}$ above the uppermost sprout tip and then the pot was filled with the sand-sawdust mixture mentioned above. Control plants were inoculated with uninfested autoclaved wheat seeds. The experiment consisted of three replicates per isolate and 20 plants per replicate. The pots were arranged in randomized block design. After 3 weeks of incubation in a glasshouse maintained at 25 to $27^{\circ} \mathrm{C}$ with a $14 \mathrm{~h} / 10 \mathrm{~h}$ light/dark cycle, all potato plants were harvested and assessed for disease incidence and disease index was calculated. Based on the relative size of necrotic area on subterraneous stems, the disease rating scale was as follows: $0=$ no disease, $1=$ less than $10 \%, 2=10$ to $50 \%, 3=50$ to $100 \%$, and $4=$ plants dead. The disease incidence and the disease index were calculated as follows: disease incidence $=$

Table 1. Information of representative binucleate Rhizoctonia isolates for anastomosis testing and phylogenetic analysis

\begin{tabular}{|c|c|c|c|c|c|}
\hline AG & Isolate & GenBank accession number & Host & Origin & Collector \\
\hline A & C-538 & AB196640 & Potato & Japan & Oniki \\
\hline A & AH-1 & AB196639 & Peanut & Japan & Ogoshi \\
\hline A & FuK-600 & AB196663 & Rose & Japan & Hyakumachi \\
\hline $\mathrm{Ba}$ & C-484 & AB196641 & Rice & Japan & Oniki \\
\hline $\mathrm{Ba}$ & Scl-2 & AB286930 & Rice & Japan & Ogoshi \\
\hline $\mathrm{Bb}$ & C-455 & AF354087 & Rice & Japan & Oniki \\
\hline $\mathrm{Bb}$ & C-350 & AB 122144 & Rice & Japan & Oniki \\
\hline Bo & RU89-1 & DQ102431 & Soil & USA & Sneh \\
\hline Bo & C-302 & AB219143 & Soil & Japan & Oniki \\
\hline $\mathrm{C}$ & OR706 & AJ242894 & Gymnadenia & Japan & Tsutsui \\
\hline $\mathrm{C}$ & $55 \mathrm{D} 25$ & AB290021 & Sugar beet & Japan & Uchino \\
\hline $\mathrm{C}$ & Ao-1-2 & AB290020 & Soil & Japan & Ogoshi \\
\hline DI & YC-SDS-1 & AB198699 & Zoysia & Japan & Tanaka \\
\hline DI & Ayu-WP-1 & AB198703 & Agrostis & Japan & Tanaka \\
\hline DII & YG-EF-1 & AB198704 & Zoysia & Japan & Tanaka \\
\hline DII & MW-EF-1 & AB198708 & Zoysia & Japan & Tanaka \\
\hline DII & TAK-14KT & AB214367 & Zoysia & Japan & Hayakawa \\
\hline DIII & KAG-9R & AB198709 & Zoysia & Japan & Hayakawa \\
\hline DIII & KOU04-12FW & AB198713 & Zoysia & Japan & Hayakawa \\
\hline $\mathrm{E}$ & Oc-1 & AB290019 & Oxalis & Japan & Ogoshi \\
\hline $\mathrm{E}$ & BN74 & AF354083 & Erigeron & USA & Burpee \\
\hline $\mathrm{E}$ & RH-155 & Unknown & Beet & Japan & Ogoshi \\
\hline $\mathrm{Fa}$ & PS-17 & AB219144 & Pea & Japan & Ogoshi \\
\hline $\mathrm{Fa}$ & Str10 & DQ102434 & Strawberry & Israel & Sneh \\
\hline $\mathrm{Fb}$ & AH-6 & AB196645 & Peanut & Japan & Ogoshi \\
\hline $\mathrm{Fb}$ & FKO2-28 & AB219145 & Soil & Japan & Ogoshi \\
\hline $\mathrm{G}$ & Str15 & DQ102396 & Strawberry & Israel & Sneh \\
\hline G & AH-9 & AB196646 & Peanut & Japan & Ogoshi \\
\hline $\mathrm{H}$ & STC-9 & AF354089 & Soil & Japan & Ogoshi \\
\hline $\mathrm{H}$ & STC-10 & AB 196648 & Soil & Japan & Ogoshi \\
\hline $\mathrm{H}$ & STC-11 & AB196649 & Soil & Japan & Ogoshi \\
\hline I & FKO-6-7 & AB290022 & Soil & Japan & Ogoshi \\
\hline I & FKO-1-17 & AB196651 & Soil & Japan & Ogoshi \\
\hline I & AV-2 & AB 196650 & Artemisia & Japan & Ogoshi \\
\hline $\mathrm{K}$ & AC-1 & AB 122145 & Onion & Japan & Ogoshi \\
\hline K & SH-10 & AB 196652 & Soil & Japan & Ogoshi \\
\hline $\mathrm{K}$ & $55 \mathrm{D} 45$ & Unknown & Sugar beet & Japan & Ogoshi \\
\hline $\mathrm{L}$ & FKO-2-26 & AB196653 & Soil & Japan & Ogoshi \\
\hline $\mathrm{L}$ & FKO-2-11 & AB286934 & Soil & Japan & Ogoshi \\
\hline $\mathrm{L}$ & FKO-2-16 & AB286933 & Soil & Japan & Ogoshi \\
\hline $\mathrm{O}$ & FKO-6-2 & AF354094 & Soil & Japan & Ogoshi \\
\hline $\mathrm{O}$ & FKO-2-10 & AB286936 & Soil & Japan & Ogoshi \\
\hline $\mathrm{P}$ & C-584 & AB286938 & Soil & Japan & Oniki \\
\hline $\mathrm{P}$ & $\mathrm{Xb}-3$ & AB286939 & Ginger & China & Yang \\
\hline $\mathrm{P}$ & C-578 & AB196654 & Tea & Japan & Takaya \\
\hline Q & C-620 & AF354095 & Cynodon & Japan & Oniki \\
\hline $\mathrm{R}$ & BN-37 & AB219146 & Cucumber & USA & Burpee \\
\hline $\mathrm{R}$ & X4-3 & AB286942 & Ginger & China & Yang \\
\hline $\mathrm{S}$ & Bn 22 & AF354084 & Pittosporum & USA & Burpee \\
\hline $\mathrm{S}$ & RhJN2073WCz5 & HQ269814 & Azalea & USA & Copes \\
\hline $\mathrm{U}$ & MWR-20 & AB196664 & Rose & Japan & Hyakumachi \\
\hline \multirow[t]{7}{*}{$\mathrm{U}$} & MWR-22 & AB196666 & Rose & Japan & Hyakumachi \\
\hline & KMJ-14-1 & KM387384 & Ginger & China & Yang \\
\hline & KMYT-2-8-1 & KM275622 & Cocoyam & China & Yang \\
\hline & LDDL02-1 & KF907736 & Brassica & Vietnam & Hua \\
\hline & B13 & JX135076 & Poplar & France & Didier-Lacercat \\
\hline & CMH555 & KF800644 & Indoor air & USA & Rittenour \\
\hline & R107 & JQ676926 & Canola & Canada & Zhou \\
\hline
\end{tabular}


$100 \% \times\left(n_{1}+n_{2}+n_{3}+n_{4}\right) / N$ and disease index $=100 \times\left(0 n_{0}+1 n_{1}+2 n_{2}+\right.$ $\left.3 n_{3}+4 n_{4}\right) /(4 N)$, where $n_{0}$ to $n_{4}$ is the number of plants in each disease rating category and $N$ is the total number of inoculated plants. Isolates were made from all visible lesions on subterraneous potato stems and the resulting Rhizoctonia isolates were identified by morphological and molecular methods mentioned above to fulfill Koch's postulates. The experiment was repeated once.

\section{Results}

Fungal isolation and anastomosis grouping. Two Rhizoctonia isolates designated as HL-CZ and HL-ZA were recovered from diseased potato stems that were collected from two separate fields in Kedong county of Heilongjiang Province. Nuclear staining with DAPI revealed that they had two nuclei per cell. When paired with BNR reference strains, isolates HL-CZ and HL-ZA gave C1 reactions with AG-A and AG-K, while they gave $\mathrm{C} 0$ reactions with all other AGs. When the two isolates were paired with each other, a C2 reaction was observed, indicating that they belonged to the same AG.

Morphological characteristics. The mean widths of 20 mature hyphae of isolates HL-CZ and HL-ZA were $4.54 \pm 0.48 \mu \mathrm{m}$ (ranged from 3.88 to $5.52 \mu \mathrm{m}$ ) and $4.79 \pm 0.49 \mu \mathrm{m}$ (ranged from 4.08 to $5.63 \mu \mathrm{m})$, respectively. The mycelia of two isolates growing on PDA were floccose and remained white after growing for 3 weeks. Concentric rings were visible in cultures of isolate HL-CZ (Fig. 1A), whereas this zonation was not observed in isolate HL-ZA (Fig. 1B). Both isolates produced white monilioid cells in their fluffy aerial hyphae, but no sclerotia formed during the incubation of 21 days at $25^{\circ} \mathrm{C}$. Despite repeated attempts, neither of the two isolates could be induced to produce hymenia or basidiospores on $2 \% \mathrm{WA}, 2 \% \mathrm{~V} 8$ juice agar, or on soil overlay dishes. Both isolates were able to grow from 5 to $30^{\circ} \mathrm{C}$ on PDA media (Fig. 2). The optimum temperature for hyphal growth of HL-ZA and HL-CZ was $25^{\circ} \mathrm{C}$ with mean radial growth of $19.8 \pm 0.2 \mathrm{~mm} /$ day and $17.2 \pm 0.5 \mathrm{~mm} /$ day, respectively. The isolates grew very slowly at $35^{\circ} \mathrm{C}$ and stopped growing at 0 or $40^{\circ} \mathrm{C}$.

rDNA-ITS RFLP and sequence analysis. PCR amplification of the rDNA-ITS regions with primers ITS1 and ITS4 produced a single fragment for each of binucleate Rhizoctonia isolates in this study. The length of the PCR products of the two isolates was estimated at $670 \mathrm{bp}$. When digested with enzymes EcoRI, HaeIII, HapII, HhaI, HinfI, and MboI, respectively, isolates HL-CZ and HL-ZA shared the same unique banding patterns that clearly distinguished them from all reference strains. The PCR products were not cleaved by enzyme HapII except for those of AG-C, AG-DI, AG-DIII, AG-I, and AG-K. The EcoRI digested PCR products of all isolates into two fragments of different lengths, indicating one restriction site in each isolate. HhaI digestion also indicated that all AGs had one restriction site, except for AG-Bb and AG-Q. The enzyme HhaI digested isolates of AG-Bb and AG-Q into three different-sized fragments. HaeIII, HinfI, and $M b o$ I digestion showed a variety of polymorphisms among all AGs.

The PCR products of isolates HL-ZA and HL-CZ were successfully sequenced and the resulting sequences deposited in GenBank as accession numbers of KP281807 and KP281808, respectively. Cluster analysis based on rDNA-ITS sequences of the isolates from this study and of known AGs retrieved from GenBank revealed that
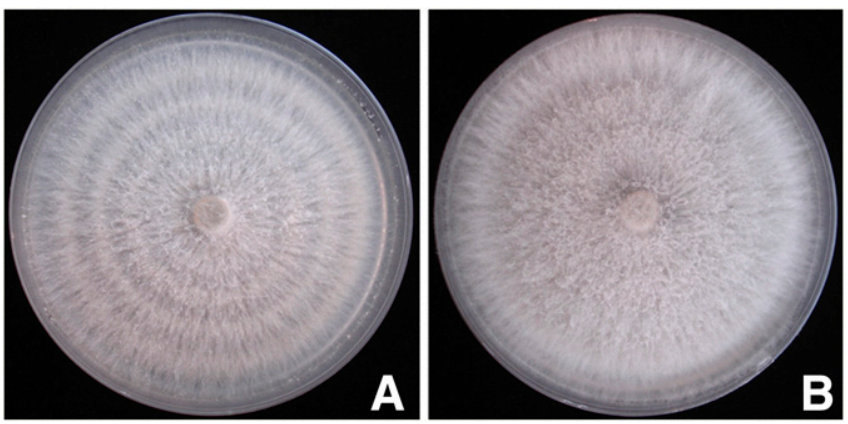

Fig. 1. Cultural morphology of the two binucleate Rhizoctonia isolates after 14 days of incubation on potato dextrose agar in the dark. A, HL-CZ. B, HL-ZA. most isolates belonging to the same AG were clustered individually in the phylogenetic tree with support of high bootstrap value (Fig. 3). A few isolates belonging to different AGs, such as AG-P and AG-U, AG-C and AG-I, were located in the same cluster. In this ML tree, isolates HL-ZA and HL-CZ were grouped into a distinct clade with unknown AGs of Rhizoctonia isolates B13 (JX135076), R107

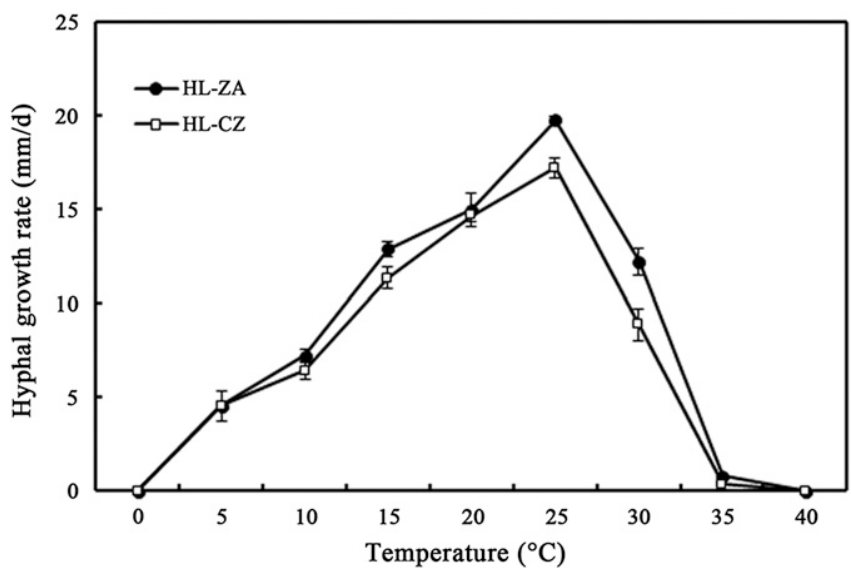

Fig. 2. Effect of temperature on radial growth rate of isolates HL-ZA and HL-CZ grown on potato dextrose agar in the dark. Bar shows a standard error.

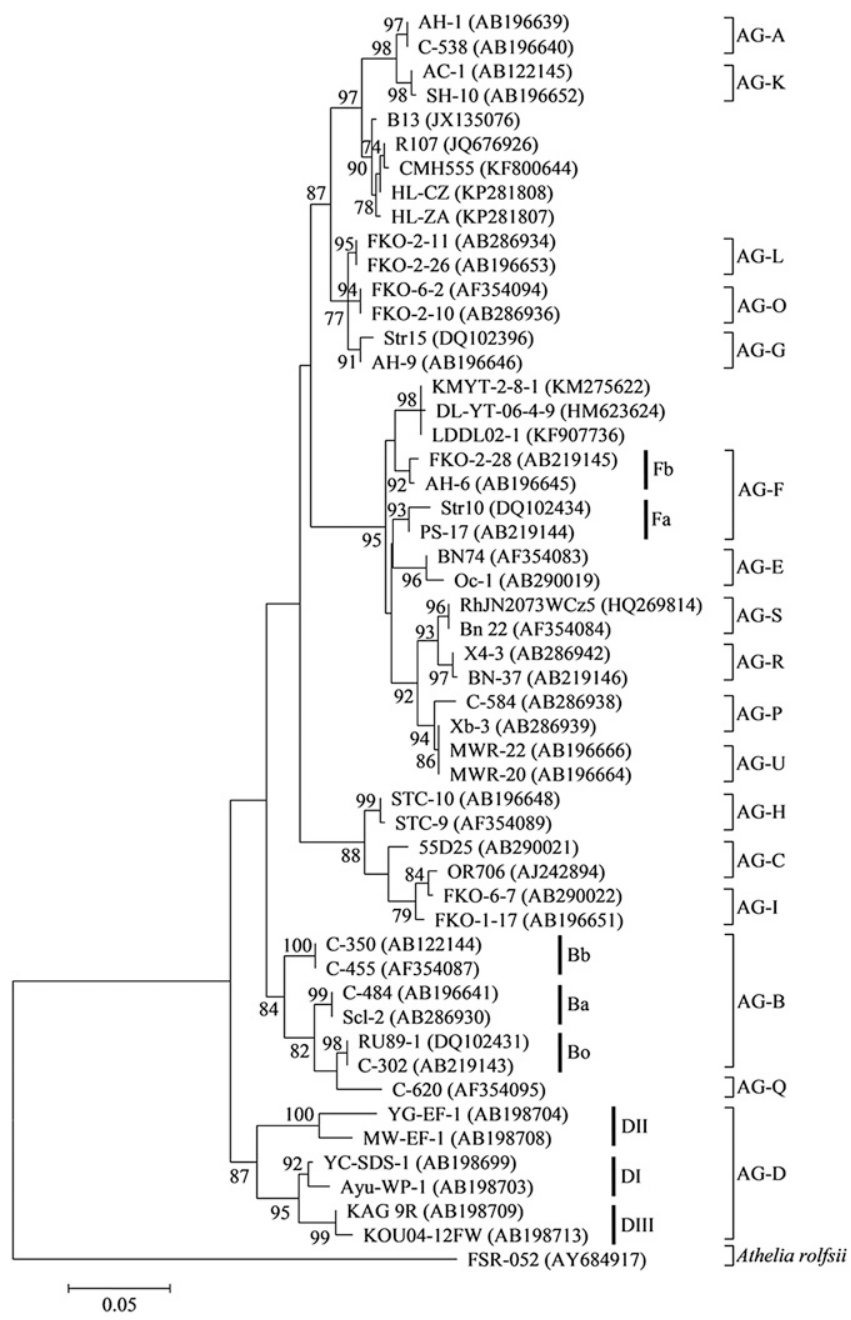

Fig. 3. Phylogenetic tree generated from the comparison of rDNA-ITS sequences of isolates HL-ZA and $\mathrm{HL}-\mathrm{CZ}$ from this study and those of binucleate Rhizoctonia isolates from GenBank. Bootstrap values (1,000 replicates) greater than 70 are shown above the branches. Scale bar represents a genetic distance of 0.05 for horizontal branch lengths. 
(JQ676926), and CMH555 (KF800644), which were from France, Canada, and the United States, respectively. The percent identity of the rDNA-ITS region between HL-CZ and HL-ZA was 99.2\%. When compared with each of the other AGs, sequence similarity levels ranged from 73.2 to $90.0 \%$ (Table 2). AG-V isolates KMYT-2-8-1 (KM275622) and DL-YT-06-4-9 (HM623624) clustered with isolate LDDL02-1 (KF907736) from Vietnam, which was described as AGFc in GenBank. The groups of AG-Fc and AG-V closely related to $\mathrm{AG}-\mathrm{Fb}$ in the ML tree.

Pathogenicity determination. Pathogenicity tests were performed twice with similar results. Control plants remained asymptomatic (Fig. 4A) and no Rhizoctonia isolates were reisolated from them. On the other hand, potato plants inoculated with isolates HL-CZ and HL-ZA showed symptoms of brown, dry, and slightly sunken lesions (Fig. 4B and C), which were similar to those observed on diseased stems collected from the fields. The disease incidence caused by isolate HL-ZA was $28.70 \pm 4.24 \%$, while that caused by isolate HL-CZ was $26.19 \pm 2.32 \%$. The disease indexes caused by the two isolates were $7.59 \pm 0.70$ and $6.93 \pm 1.04$, respectively. There was no significant difference in aggressiveness between the two isolates. BNR isolates were consistently reisolated from the artificially inoculated plants and their identities were confirmed by morphological and molecular characteristics as described above, fulfilling Koch's postulates.

\section{Discussion}

In this study, two BNR isolates were recovered from cankered subterraneous potato stems that were collected from Heilongjiang Province, northeastern China. When paired with reference strains, they failed to anastomose with BNR isolates from AG-A to AG-Q and AG-U. However, the two isolates could anastomose with each other, indicating that they belonged to the same AG. RFLP analysis of the rDNA-ITS region revealed that they differed from these known BNR AGs. The RFLP banding patterns and fragment sizes of the reference strains in this research were similar with those reported by Toda et al. (1999) using the same enzymes. In the phylogenetic tree, the isolates HL-CZ and HL-ZA were clustered into a distinct group, which was closely related to AG-A and AG-K as they originated from one clade. All these results strongly indicated that the two isolates belonged to a new BNR AG. The sequence similarity of the rDNA-ITS region between the new AG and AG-R or AG-S was less than $80 \%$. Since isolates within the same AG or subgroup are likely to locate in a cluster in the phylogenetic tree and their rDNA-ITS regions are 95 to $100 \%$ similarity (Sharon et al. 2008), the isolates B13, R107, and CMH555 may also belong to this new BNR AG.

Twenty-two BNR AGs named with alphabetic characters (from A to V) have been reported (Dong et al. 2013; Hyakumachi et al. 2005; Ogoshi et al. 1983; Sneh et al. 1991). Among these AGs, AG-J, AG$\mathrm{M}, \mathrm{AG}-\mathrm{N}$, and AG-T have been confirmed to be invalid (Cubeta et al. 1991; Sharon et al. 2008; Sneh et al. 1991); AG-I and AG-C, AG-U and AG-P were suggested to combine into one AG, respectively (Sharon et al. 2008; Sneh et al. 1991); AG-V has not been officially published and the phylogenetic tree in this study showed that the represented isolates KMYT-2-8-1 (KM275622) and DL-YT-06-4-9 (HM623624) were closely related to AG-Fb. To avoid confusion,
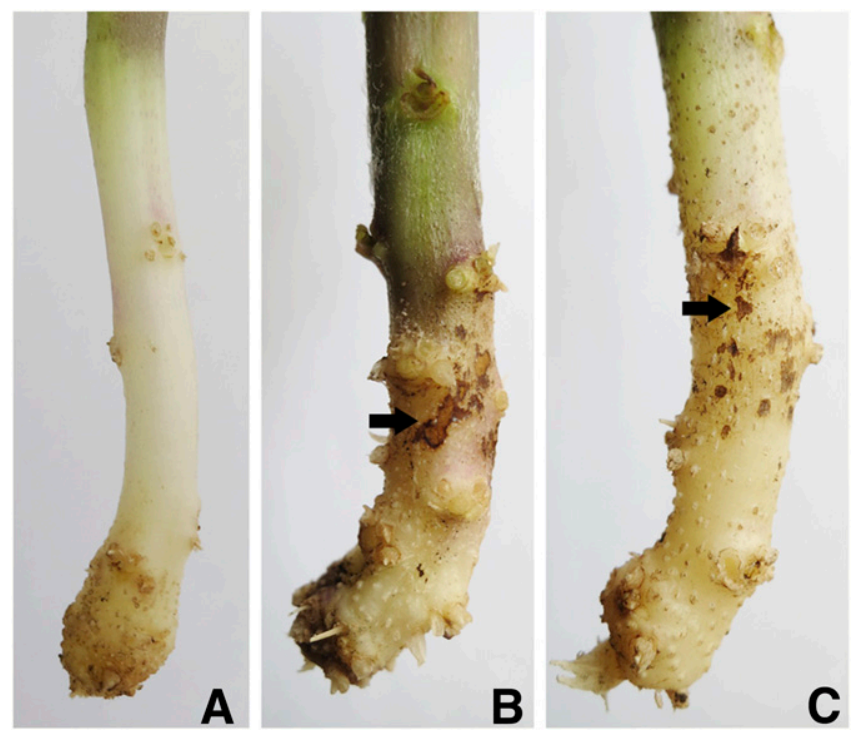

Fig. 4. Symptoms of stem canker on potato subterranean stems caused by isolates HL-ZA and HL-CZ. A, Healthy control plants. B and C, Diseased stems induced by isolates $\mathrm{HL}-\mathrm{ZA}$ and $\mathrm{HL}-\mathrm{CZ}$, respectively. Arrows indicate brown and sunken lesions.

Table 2. Matrix of percent sequence similarity of the internal transcribed spacer region between anastomosis groups and subgroups

\begin{tabular}{|c|c|c|c|c|c|c|c|c|c|c|c|c|c|c|c|c|c|c|c|c|c|c|c|c|}
\hline & $\mathbf{Z A}$ & $\mathbf{C Z}$ & $\mathbf{A}$ & Ba & $\mathbf{B b}$ & Bo & C & DI & DII & DIII & $\mathbf{E}$ & Fa & $\mathbf{F b}$ & G & $\mathbf{H}$ & I & $\mathbf{K}$ & $\mathbf{L}$ & O & $\mathbf{P}$ & $\mathbf{Q}$ & $\mathbf{R}$ & $\mathbf{S}$ & $\mathbf{U}$ \\
\hline $\mathrm{CZ}$ & 99.2 & & & & & & & & & & & & & & & & & & & & & & & \\
\hline A & 88.7 & 88.8 & & & & & & & & & & & & & & & & & & & & & & \\
\hline $\mathrm{Ba}$ & 78.4 & 78.5 & 79.7 & & & & & & & & & & & & & & & & & & & & & \\
\hline $\mathrm{Bb}$ & 75.2 & 75.3 & 74.9 & 84.2 & & & & & & & & & & & & & & & & & & & & \\
\hline Bo & 79.0 & 79.1 & 80.2 & 92.6 & 84.0 & & & & & & & & & & & & & & & & & & & \\
\hline $\mathrm{C}$ & 78.8 & 79.1 & 80.0 & 81.9 & 77.0 & 83.1 & & & & & & & & & & & & & & & & & & \\
\hline DI & 73.6 & 73.7 & 75.1 & 77.8 & 76.9 & 79.9 & 79.0 & & & & & & & & & & & & & & & & & \\
\hline DII & 74.6 & 74.6 & 75.6 & 77.2 & 76.0 & 79.9 & 78.6 & 85.6 & & & & & & & & & & & & & & & & \\
\hline DIII & 73.2 & 73.3 & 73.9 & 76.6 & 74.3 & 79.0 & 78.0 & 91.9 & 83.1 & & & & & & & & & & & & & & & \\
\hline E & 79.1 & 79.2 & 79.2 & 77.0 & 74.1 & 77.4 & 76.7 & 73.7 & 73.1 & 72.6 & & & & & & & & & & & & & & \\
\hline $\mathrm{Fa}$ & 79.1 & 79.0 & 79.3 & 77.4 & 74.7 & 78.1 & 77.2 & 73.9 & 73.2 & 73.1 & 90.2 & & & & & & & & & & & & & \\
\hline $\mathrm{Fb}$ & 78.8 & 78.9 & 77.9 & 77.0 & 75.2 & 77.8 & 76.6 & 74.5 & 73.1 & 73.7 & 87.7 & 88.2 & & & & & & & & & & & & \\
\hline G & 84.1 & 84.3 & 84.5 & 79.3 & 75.4 & 79.5 & 81.1 & 76.5 & 75.1 & 75.5 & 81.5 & 81.3 & 81.7 & & & & & & & & & & & \\
\hline $\mathrm{H}$ & 78.6 & 78.7 & 80.4 & 81.0 & 76.4 & 82.3 & 92.5 & 78.7 & 77.5 & 77.3 & 76.0 & 77.0 & 76.6 & 79.7 & & & & & & & & & & \\
\hline I & 78.5 & 78.6 & 79.5 & 81.5 & 77.0 & 82.5 & 95.0 & 78.6 & 78.2 & 77.6 & 76.1 & 76.7 & 76.6 & 80.7 & 92.1 & & & & & & & & & \\
\hline $\mathrm{K}$ & 89.9 & 90.0 & 92.2 & 79.0 & 75.7 & 79.0 & 78.2 & 75.0 & 75.7 & 73.8 & 79.6 & 78.7 & 77.2 & 82.8 & 78.1 & 78.1 & & & & & & & & \\
\hline $\mathrm{L}$ & 84.8 & 85.0 & 85.9 & 80.5 & 76.5 & 80.5 & 81.2 & 77.0 & 75.9 & 75.8 & 81.5 & 81.7 & 82.8 & 95.9 & 80.7 & 81.0 & 84.3 & & & & & & & \\
\hline $\mathrm{O}$ & 84.7 & 84.9 & 85.6 & 79.5 & 75.9 & 80.0 & 81.2 & 77.0 & 75.1 & 75.8 & 82.1 & 82.0 & 82.8 & 95.9 & 80.1 & 80.5 & 83.8 & 97.4 & & & & & & \\
\hline $\mathrm{P}$ & 77.5 & 77.5 & 77.2 & 74.8 & 73.1 & 75.4 & 75.6 & 73.0 & 71.9 & 72.3 & 85.5 & 86.1 & 86.3 & 79.6 & 74.7 & 75.2 & 77.1 & 79.8 & 80.6 & & & & & \\
\hline Q & 75.3 & 75.3 & 76.1 & 87.0 & 84.0 & 90.9 & 79.3 & 76.9 & 77.1 & 74.8 & 74.5 & 74.9 & 75.9 & 75.6 & 78.8 & 79.0 & 75.6 & 76.6 & 76.0 & 72.8 & & & & \\
\hline $\mathrm{R}$ & 75.8 & 75.7 & 73.9 & 74.0 & 73.2 & 74.0 & 74.0 & 71.9 & 70.7 & 71.4 & 83.2 & 83.7 & 84.4 & 77.2 & 72.9 & 73.5 & 74.5 & 78.4 & 78.3 & 87.3 & 73.6 & & & \\
\hline S & 76.6 & 76.5 & 75.7 & 74.5 & 73.7 & 74.3 & 74.3 & 71.9 & 70.9 & 71.4 & 85.1 & 85.2 & 84.8 & 79.2 & 73.6 & 74.2 & 76.3 & 80.0 & 80.3 & 88.1 & 73.1 & 90.8 & & \\
\hline $\mathrm{U}$ & 77.5 & 77.4 & 77.4 & 74.7 & 73.2 & 75.2 & 75.2 & 72.7 & 71.4 & 72.1 & 85.3 & 86.1 & 86.0 & 79.5 & 74.3 & 74.7 & 76.9 & 79.6 & 80.5 & 97.5 & 72.8 & 88.0 & 87.9 & \\
\hline V & 78.0 & 78.2 & 78.1 & 77.2 & 76.0 & 77.8 & 77.0 & 75.0 & 72.9 & 72.8 & 88.4 & 88.7 & 91.2 & 81.3 & 76.5 & 76.8 & 77.0 & 82.1 & 82.5 & 85.5 & 76.2 & 83.7 & 84.1 & 85.7 \\
\hline
\end{tabular}


AG-W is being proposed for the AG of new BNR. Considering only the three letters $\mathrm{X}, \mathrm{Y}$, and $\mathrm{Z}$ are available in this naming system for potential new BNR AGs in the future, it is necessary to reorganize BNR AGs, although this work needs stronger international cooperation.

Environmental conditions may influence the prevalence of certain AGs (Virgen-Calleros et al. 2000). For example, as causal agents of potato stem canker, $R$. solani isolates of AG-4 and AG-5 are common in warm environments, whereas AG-3 prefers cooler and drier conditions (Anguiz and Martin 1989). Compared with BNR isolates of AG-A and AG-K recovered from cankered potato stems throughout China (Yang et al. 2014), AG-W isolates were only obtained from Kedong county in Heilongjiang Province, where the temperature ranged from 9 to $28^{\circ} \mathrm{C}$ during the potato growing season. Our research showed that the isolates HL-CA and HL-ZA grew very well from 10 to $30^{\circ} \mathrm{C}$ with optimum temperature at $25^{\circ} \mathrm{C}$. The mycelia grew very slow when temperature was higher than $35^{\circ} \mathrm{C}$ and stopped growing at $40^{\circ} \mathrm{C}$, indicating that $\mathrm{AG}-\mathrm{W}$ isolates may prefer cool conditions.

Isolates assigned to different anastomosis groups may vary in host range (Sneh et al. 1991). It was reported that some AGs and subgroups of $R$. solani were shown to be host-specific. For example, AG-3 isolates are specialized to solanaceous crops (Banville et al. 1996; Bartz et al. 2010), and AG-8 predominantly infects cereals causing the "bare patch" disease (Ogoshi et al. 1990; Roget, 1995; Smiley and Uddin 1993). BNR AG-B isolates also showed host specificity as they infect species belonging to the family Gramineae (Sneh et al. 1991). Of the isolates clustering within one clade, isolates HL-CZ and HL-ZA were confirmed to cause brown, dry, and slightly sunken lesions on underground potato stems, which were similar to those induced by other BNR isolates (Yang et al. 2014). Isolate CMH555 was recovered from indoor air, and isolates B13 and R107 originated from poplar and canola, respectively, but their pathogenicity on these two hosts is unclear. Whether the isolates HL-CZ and HL-ZA (AG-W) are host species-specific or not warrants further research.

\section{Acknowledgments}

We are grateful to N. Kondo for kindly providing the reference strains. Mention of trade names or commercial products in this report is solely for the purpose of providing specific information and does not imply recommendation or endorsement.

\section{Literature Cited}

Ahvenniemi, P., Wolf, M., Lehtonen, M. J., Wilson, P., German-Kinnari, M., and Valkonen, J. P. T. 2009. Evolutionary diversification indicated by compensatory base changes in ITS2 secondary structures in a complex fungal species, Rhizoctonia solani. J. Mol. Evol. 69:150-163.

Anguiz, R., and Martin, C. 1989. Anastomosis groups, pathogenicity, and other characteristics of Rhizoctonia solani isolated from potatoes in Peru. Plant Dis. 73:199-201.

Bandoni, R. J. 1979. Safranin O as a rapid stain for fungi. Mycologia 71:873-874.

Banville, G. J., Carling, D. E., and Otrysko, B. E. 1996. Rhizoctonia diseases on potato. Pages 321-330. in: Rhizoctonia species: taxonomy, molecular biology, ecology, pathology, and disease control. B. Sneh, S. Jabaji-Hare. S. Neate and G. Dijst, eds. Kluwer Academic Publishers, Dordrecht, The Netherlands.

Bartz, F. E., Cubeta, M. A., Toda, T., Naito, S., and Ivors, K. L. 2010. An in planta method for assessing the role of basidiospores in Rhizoctonia foliar disease of tomato. Plant Dis. 94:515-520.

Burpee, L. L., Sanders, P. L., Cole, H., Jr., and Sherwood, R. T. 1980. Anastomosis groups among isolates of Ceratobasidium cornigerum and related fungi. Mycologia 72:689-701.

Carling, D. E. 1996. Grouping in Rhizoctonia solani by hyphal anastomosis reaction. Pages 37-47 in: Rhizoctonia species: taxonomy, molecular biology, ecology, pathology, and disease control. B. Sneh, S. Jabaji-Hare. S. Neate and G. Dijst, eds. Kluwer Academic Publishers, Dordrecht, The Netherlands.

Carling, D. E., Pope, E. J., Brainard, K. A., and Carter, D. A. 1999. Characterization of mycorrhizal isolates of Rhizoctonia solani from an orchid, including AG-12, a new anastomosis group. Phytopathology 89: 942-946.

Copes, W. E., Rodriguez-Carres, M., Toda, T., Rinehart, T. A., and Cubeta, M. A. 2011. Seasonal prevalence of species of binucleate Rhizoctonia fungi in growing medium, leaf litter, and stems of container-grown Azalea. Plant Dis. 95:705-711.
Cubeta, M. A., Echandi, E., Abenerthy, T., and Vilgalys, R. 1991. Characterization of anastomosis groups of binucleate Rhizoctonia species using restriction analysis of ribosomal RNA gene. Phytopathology 81:1395-1400.

Dong, W. H., Li, Y. Q., Duan, C. F., Naito, S., Conner, R. L., Yang, G. H., and Li, C. Y. 2013. Identification of AG-V, a new anastomosis group of binucleate Rhizoctonia spp. from taro and ginger in Yunnan province. Page 46 in: $5^{\text {th }}$ International Symposium on Rhizoctonia: Progress and Challenges in the $21^{\text {st }}$ Century.

Fang, X. L., Finnegan, P. M., and Barbetti, M. J. 2013. Wide variation in virulence and genetic diversity of binucleate Rhizoctonia isolates associated with root rot of strawberry in Western Australia. PLoS One 8:E55877.

Gonzalez, D., Carling, D. E., Kuninaga, S., Vilgalys, R., and Cubeta, M. A. 2001. Ribosomal DNA systematics of Ceratobasidium and Thanatephorus with Rhizoctonia anamorphs. Mycologia 93:1138-1150.

González Garcia, V., Portal Onco, M. A., and Rubio Susan, V. 2006. Review. Biology and systematics of the form genus Rhizoctonia. Span. J. Agric. Res. 4:55-79.

Hall, T. 2011. BioEdit: An important software for molecular biology. GERF Bull. Biosci. 2:60-61.

Hayakawa, T., Toda, T., Ping, Q., Mghalu, J. M., Yaguchi, S., and Hyakumachi, M. 2006. A new subgroup of Rhizoctonia AG-D, AG-D III, obtained from Japanese zoysia grass exhibiting symptoms of a new disease. Plant Dis. 90: $1389-1394$

Hyakumachi, M., Priyatmojo, A., Kubota, M., and Fukui, H. 2005. New anastomosis groups, AG-T and AG-U, of binucleate Rhizoctonia spp. causing root and stem rot of cut-flower and miniature roses. Phytopathology 95: 784-792.

Kronland, W. C., and Stanghellini, M. E. 1988. Clean slide technique for the observation of anastomosis and nuclear condition of Rhizoctonia solani. Phytopathology 78:820-822.

Lehtonen, M. J., Ahvenniemi, P., Wilson, P. S., German-Kinnari, M., and Valkonen, J. P. T. 2008. Biological diversity of Rhizoctonia solani (AG-3) in a northern potato-cultivation environment in Finland. Plant Pathol. 57:141-151.

Liu, Z. L., and Sinclair, J. B. 1993. Differentiation of intraspecific groups within anastomosis group 1 of Rhizoctonia solani using ribosomal DNA internal transcribed spacer and isozyme comparisons. Can. J. Plant Pathol. 15:272-280.

Miles, T. D., Woodhall, J. W., Miles, L. A., and Wharton, P. S. 2013. First report of a binucleate Rhizoctonia (AG-A) from potato stems infecting potatoes and sugarbeet in the Pacific Northwest. Plant Dis. 97:1657.

Ogoshi, A. 1976. Studies on the grouping of Rhizoctonia solani Kühn with hyphal anastomosis, and on the perfect stage of groups. Natl. Inst. Agric. Sci. Tokyo Jpn. Bull. Ser. C No. 30:1-63.

Ogoshi, A. 1985. Anastomosis and intraspecific groups of Rhizoctonia solani and binucleate Rhizoctonia. Fitopatol. Bras. 10:371-390.

Ogoshi, A., Cook, R. J., and Bassett, E. N. 1990. Rhizoctonia species and anastomosis groups causing root rot of wheat and barley in the Pacific Northwest. Phytopathology 80:784-788.

Ogoshi, A., Oniki, M., Araki, T., and Ui, T. 1983. Anastomosis groups of binucleate Rhizoctonia in Japan and North America and their perfect states. Trans. Mycol. Soc. Jpn. 24:79-87.

Ogoshi, A., Oniki, M., Sakai, R., and Ui, T. 1979. Anastomosis grouping among isolates of binucleate Rhizoctonia. Trans. Mycol. Soc. Jpn. 20:33-39.

Priyatmojo, A., Escopalao, V. E., Tangonan, N. G., Pascual, C. B., Suga, H., Kageyama, K., and Hyakumachi, M. 2001. Characterization of a new subgroup of Rhizoctonia solani anastomosis group 1 (AG-1-ID), causal agent of a necrotic leaf spot on coffee. Phytopathology 91:1054-1061.

Roget, D. K. 1995. Decline in root rot (Rhizoctonia solani AG-8) in wheat in a tillage and rotation experiment at Avon, South Australia. Aust. J. Exp. Agric. 35:1009-1013.

Sharon, M., Freeman, S., Kuninaga, S., and Sneh, B. 2007. Genetic diversity, anastomosis groups and virulence of Rhizoctonia spp. from strawberry. Eur. J. Plant Pathol. 117:247-265.

Sharon, M., Kuninaga, S., Hyakumachi, M., Naito, S., and Sneh, B. 2008 Classification of Rhizoctonia spp. using rDNA-ITS sequence analysis supports the genetic basis of the classical anastomosis grouping. Mycoscience 49:93-114

Sharon, M., Sneh, B., Kuninaga, S., and Hyakumachi, M. 2006. The advancing identification and classification of Rhizoctonia spp. using molecular and biotechnological methods compared with the classical anastomosis grouping. Mycoscience 47:299-316.

Smiley, R. W., and Uddin, W. 1993. Influence of soil temperature on Rhizoctonia root rot ( $R$. solani AG-8 and $R$. oryzae) of winter wheat. Phytopathology 83: 777-785.

Sneh, B., Burpee, L., and Ogoshi, A. 1991. Identification of Rhizoctonia species The American Phytopathological Society, St. Paul, MN.

Tamura, K., Peterson, D., Peterson, N., Stecher, G., Nei, M., and Kumar, S. 2011 MEGA5: molecular evolutionary genetics analysis using maximum likelihood, evolutionary distance, and maximum parsimony methods. Mol. Biol. Evol. 28: 2731-2739.

Thompson, J. D., Higgins, D. G., and Gibson, T. J. 1994. CLUSTAL W improving the sensitivity of progressive multiple sequence alignment through sequence weighting, position-specific gap penalties and weight matrix choice. Nucleic Acids Res. 22:4673-4680. 
Toda, T., Hyakumachi, M., Suga, H., Kageyama, K., Tanaka, A., and Tani, T. 1999. Differentiation of Rhizoctonia AG-D isolates from turfgrass into subgroups I and II based on rDNA and RAPD analyses. Eur. J. Plant Pathol. 105:835-846.

Virgen-Calleros, G., Olalde-Portugal, V., and Carling, D. E. 2000. Anastomosis groups of Rhizoctonia solani on potato in central México and potential for biological and chemical control. Am. J. Potato Res. 77:219-224.

Wang, P. P., and Wu, X. H. 2012. First report of sugar beet seedling damping-off caused by binucleate Rhizoctonia AG-A in China. Plant Dis. 96:1696.
White, T. J., Bruns, T., Lee, S., and Taylor, J. W. 1990. Amplification and direct sequencing of fungal ribosomal RNA genes for phylogenetics. Pages 315-322 in: PCR protocols: A guide to methods and applications. M. A. Innis, D. H. Gelfand, J. J. Sninsky, and T. J. White, eds. Academic Press, San Diego, CA.

Yang, Y. G., and Wu, X. H. 2013. First report of potato stem canker caused by binucleate Rhizoctonia AG-A in Jilin Province, China. Plant Dis. 97:1246.

Yang, Y. G., Zhao, C., Guo, Z. J., and Wu, X. H. 2014. Anastomosis groups and pathogenicity of binucleate Rhizoctonia isolates associated with stem canker of potato in China. Eur. J. Plant Pathol. 139:535-544. 